\title{
Ictiofauna do Ribeirão do Pântano, afluente do Rio Mogi-Guaçu, Bacia do Alto Rio Paraná, São Paulo, Brasil
}

\author{
Odynei R. Perez-Junior \& Júlio C. Garavello
}

Universidade Federal de São Carlos, Departamento de Ecologia e Biologia Evolutiva, Laboratório de Ictiologia Sistemática. Via Washington Luís km 235, Caixa Postal 676, 13565-905, São Carlos, SP, Brasil. (odneyjr@ig.com.br, garavelo@power.ufscar.br)

\begin{abstract}
Ichthyofauna of Pântano stream, tributary of Mogi-Guaçu river, alto Paraná river basin, São Paulo, Brazil. The fish assemblages from Pântano stream were studied monthly from May 2000 to June 2001 and the composition, longitudinal distribution and constancy of fish species are described. Samples were performed in three different sites, using gill nets, sieves, cast net and trawl net. Sixty-three species of 46 genera, pertaining to 18 families were identified. Characiformes with 30 species $(47.62 \%)$ and Siluriformes with $22(34.92 \%)$ were the more specious orders. Five species of Perciformes, three species of Gymnotiformes, two species of Cyprinodontiformes, and only a single Synbranchiformes species were registered.
\end{abstract}

KEYWORDS. Upper Rio Paraná, Mogi-Guaçu river basin, longitudinal distribution, freshwater fishes, seasonality.

RESUMO. As assembléias de peixes do ribeirão do Pântano, São Paulo, Brasil foram estudadas mensalmente entre os meses de maio de 2000 e junho de 2001. Estudos sobre sua composição, distribuição longitudinal e constância das espécies de peixes foram realizados. Foram feitas coletas da ictiofauna com auxilio de redes de espera, peneiras, tarrafas e redes de arrasto em três diferentes pontos do ribeirão. Sessenta e três espécies pertencentes a 46 gêneros de 18 famílias foram identificadas. As ordens Characiformes (com 30 espécies registradas, representando $47,62 \%$ da ictiofauna) e Siluriformes com 22 espécies, (34,92\% do total), foram as ordens melhor representadas no elenco das espécies do ribeirão do Pântano. Cinco espécies pertencentes a ordem Perciformes, três a ordem Gymnotiformes, duas a Cyprinondontiformes e uma de Synbranchiformes também foram encontradas.

PAlAVRAS-CHAVE. Alto rio Paraná, rio Mogi-Guaçu, distribuição longitudinal, peixes de água doce, sazonalidade.

A ictiofauna da bacia do rio Mogi-Guaçu pode ser considerada uma das mais conhecidas na bacia do alto rio Paraná. Autores como IHERING $(1929,1930)$, SCHUBART (1943, 1962, 1964a, 1964b), Godoy $(1954,1962)$, NoMURA et al. (1972), Nomura \& MüELLER (1980), GaLleti Jr. et al. (1990), Esteves \& Galleti JR. (1995) e Meschiatti (1995) estudaram a ictiofauna da calha principal da bacia assim como das lagoas marginais, incluindo contribuições pontuais sobre conjuntos de espécies ou interessados nas espécies de importância pesqueira sem, contudo, analisar itens biológicos como a constância, a distribuição longitudinal e a sazonalidade da ictiofauna.

Na América do Sul é reduzido o número de trabalhos versando sobre distribuição longitudinal, composição das espécies e ecologia trófica, sendo ainda limitado o número de rios e riachos estudados (Gomes \& Azevedo, 1960; UiedA, 1984; GarutTI, 1988; SABino \& CASTRO, 1990; Pavanelli \& Caramaschi, 1997; Castro \& Casatti, 1997; e CASATti et al., 2001). Garutti (1988) citou o pH, a temperatura, a topografia, o volume e a velocidade da água, assim como os períodos das diferentes atividades da ictiofauna como fatores reguladores da distribuição longitudinal no córrego Barra Funda na região noroeste do Estado de São Paulo. Casatti \& Castro (1998) identificam adaptações morfológicas dos peixes que permitem uma melhoria na exploração dos ambientes de água corrente nas cabeceiras do rio São Francisco. Entretanto, apesar do registro de estudos dessa natureza, riachos e ribeirões afluentes do rio Mogi-Guaçu ainda não têm a composição de sua ictiofauna completamente conhecida, sendo ainda escassas as informações sobre a distribuição longitudinal de suas espécies.
Nos rios maiores, LowE-McConNelL (1999) reporta que os dados sobre a maioria dos peixes tropicais provêm principalmente daquelas espécies de maior porte, que têm importância como alimento humano. Em se tratando da bacia do Alto Paraná, deve-se levar em conta a grande ocupação urbana, industrial e agrícola da área. BÖHLKE $e t$ al. (1978) comentam que os ribeirões e riachos dessa área têm a possibilidade de ainda conter espécies endêmicas de peixes de pequeno porte e que os corpos d'água que se encontram próximos a centros urbanos também sofrem com a introdução de espécies exóticas. Esteves \& Aranha (1999) relatam que os riachos apresentam características específicas e discutem até que ponto o conhecimento já adquirido sobre a ictiofauna dos grandes rios seria aplicável aos afluentes menores.

O presente artigo apresenta um inventário da ictiofauna do ribeirão do Pântano. São levantados dados sobre a distribuição longitudinal e a freqüência sazonal das espécies objetivando contribuir com o conhecimento deste tributário do rio Mogi-Guaçu.

\section{MATERIAL E MÉTODOS}

Este estudo foi realizado no ribeirão do Pântano, que nasce na região de São Carlos, a cerca de $900 \mathrm{~m}$ de altitude $\left(22^{\circ} 05^{\prime} \mathrm{S}\right.$ e $\left.47^{\circ} 45^{\prime} \mathrm{W}\right)$. Esse ribeirão atravessa os municípios de São Carlos e Descalvado, percorrendo cerca de $45 \mathrm{~km}$ até a sua foz (Fig. 1). Os pontos de coleta foram selecionados ao longo do ribeirão e em locais acessíveis por estradas que interceptam seu curso.

As coletas mensais foram realizadas no período entre maio de 2000 a junho de 2001, visando estudar as 
assembléias de peixes ao longo de um período seco e um chuvoso, acompanhando os índices de pluviosidade regional. Estes dados foram obtidos junto à Estação Meteorológica da Embrapa Pecuária Sudeste, Fazenda

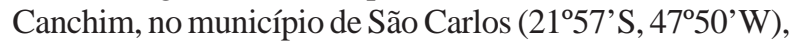
na altitude de $855 \mathrm{~m}$. A estação chuvosa compreendeu os meses de setembro de 2000 a março de 2001 e a estação seca os meses de maio a agosto de 2000 e abril a junho de 2001. A precipitação total no período foi de 1,284 mm. Os meses com maiores índices pluviométricos foram novembro e dezembro. O mês de julho de 2000 foi o mês que apresentou temperaturas mais baixas tanto mínimas como máximas (Fig. 2).

O Ponto I ( $21^{\circ} 57^{\prime} 47^{\prime}$ 'S e 47\%40'28'”W) localiza-se à montante da cachoeira do Pântano com aproximadamente $70 \mathrm{~m}$ de altura, na continuidade da Depressão Periférica regional, a $693 \mathrm{~m}$ de altitude. Nesse ponto as margens do ribeirão se encontram degradadas, ocupadas por pouca vegetação nativa e invadida pela vegetação de Brachiaria sp. (Poaceae) que pende sobre a superfície da água ou se apresenta afogada, formando áreas que se tornam locais de refúgio para a ictiofauna. O leito é um misto de pedregoso (nas corredeiras) e arenoso (nos

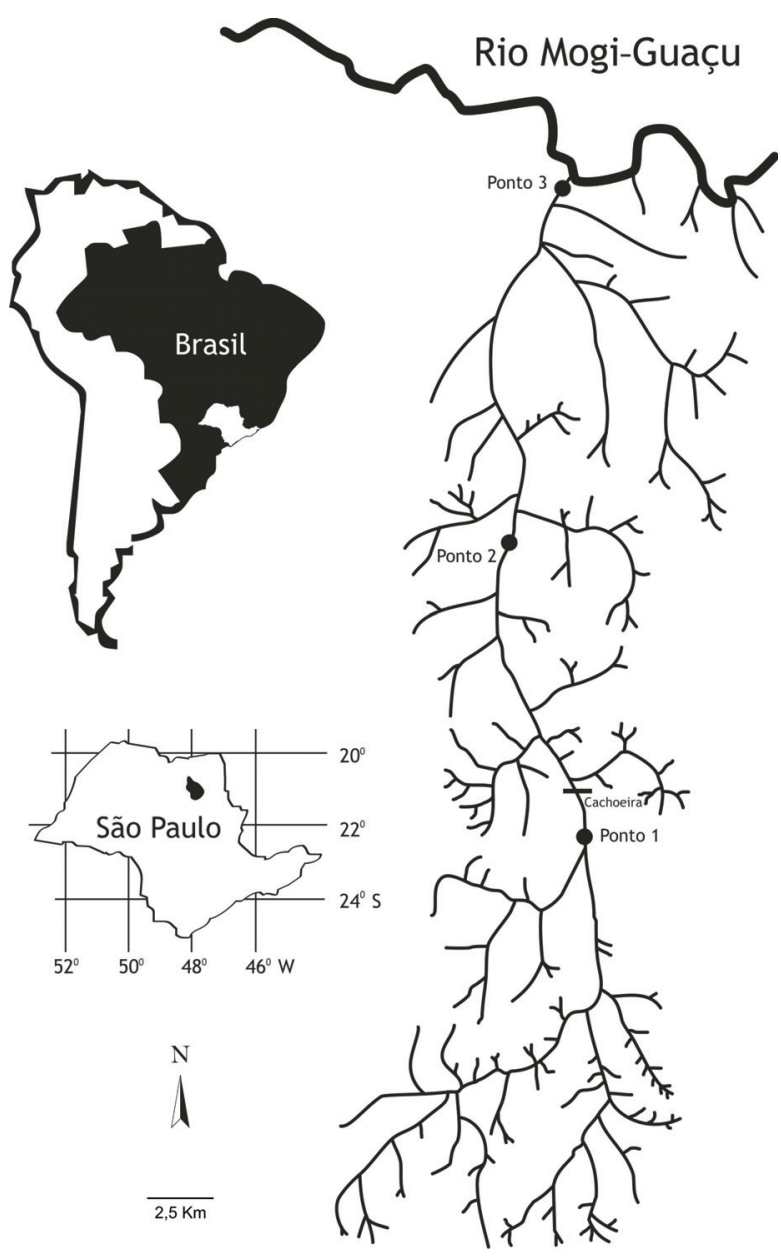

Fig. 1. Localização dos pontos de coleta no ribeirão do Pântano, afluente do rio Mogi-Guaçu, São Paulo, Brasil. locais de menor velocidade). As profundidades do local de coleta ficaram entre 0,8 a 1,20 m, considerando-se os períodos seco e úmido. A correnteza é relativamente rápida e a iluminação na maior parte da área de coleta é total, havendo poucas áreas sombreadas.

O Ponto II se localiza aproximadamente no curso médio do ribeirão (21 ${ }^{\circ} 51^{\prime} 46,5^{\prime}$ ' $\mathrm{S}$ e $47^{\circ} 40^{\prime} 25,5^{\prime}$ ' $\left.\mathrm{W}\right)$, nas vizinhanças da cidade de Descalvado e da Usina Ipiranga, a quase $560 \mathrm{~m}$ de altitude. O local de coleta apresenta sombreamentos espaçados em razão da margem direita ainda apresentar árvores e arbustos remanescentes na vegetação ribeirinha, enquanto a margem esquerda se apresenta transformada em pasto (há criação de gado). A área é circundada por fragmentos de vegetação nativa, as margens apresentam macrófitas como lírios do brejo (Hedychium sp, Zingeberaceae) e aguapés (Eichhornia sp, Pontederiaceae). A profundidade deste trecho do rio é variável, em alguns locais, mesmo em época chuvosa, a profundidade está em torno de $0,45 \mathrm{~m}$; em outros, a profundidade pode variar até a $1,90 \mathrm{~m}$. Neste ponto ocorre a formação de remansos, o que explicaria a maior deposição de sedimentos no fundo.

O Ponto III situa-se a menos de $700 \mathrm{~m} \mathrm{da}$ desembocadura do ribeirão do Pântano no rio MogiGuaçu. Esta área é composta de dois locais de amostragem: a calha do Pântano $\left(21^{\circ} 44^{\prime} 59,7^{\prime}\right.$ ' $\mathrm{S}$ e $47^{\circ} 40^{\prime} 25,5^{\prime}$ 'W) e um canal lateral $\left(21^{\circ} 45^{\prime} 00,5^{\prime}\right.$ 'S e $47^{\circ} 40^{\prime} 18,0$ ' W), situado entre um canavial e a mata ciliar do ribeirão, ambos a $530 \mathrm{~m}$ de altitude.

As margens do ribeirão do Pântano neste trecho possuem pouca vegetação. A largura da faixa de vegetação é de aproximadamente $10 \mathrm{~m}$, apresentando locais que alternam a sua densidade. A ocupação por Brachiaria sp. é grande na margem direita da calha, enquanto a margem esquerda se encontra menos invadida. Sendo a vegetação desta margem melhor preservada, quase não há insolação direta e também se verifica a presença de macrófitas. A velocidade do ribeirão neste trecho é mais elevada que no Ponto II, ocorrendo poucos locais com deposição de areia e outros sedimentos. No canal ocorre densa ocupação por Brachiaria sp, invadindo as margens da mesma maneira que nos demais pontos. A insolação é total, havendo grande quantidade de macrófitas. Por outro lado, a velocidade extremamente baixa da água no canal estaria associada à intensa sedimentação, muitas vezes formando bancos de 0,30 a $0,40 \mathrm{~m}$ de profundidade e permitindo grande visibilidade através do corpo de água.

O método de coletas foi diversificado com a utilização de vários apetrechos coletores visando amostragem qualitativa. As artes de pesca utilizadas foram: rede de arrasto de $5 \mathrm{~m}$ de comprimento, $1 \mathrm{~m}$ de altura e distância entre nós de $3 \mathrm{~mm}$; peneira de aproximadamente $1 \mathrm{~m}$ de diâmetro e malha de 1,5 mm (nos trechos rasos, onde é possível o deslocamento pelo leito do rio sondando a vegetação marginal) e redes de espera de malhas entre 1,5 e 3,0 cm entre nós adjacentes (nos remansos). Tarrafas de dois tamanhos também foram utilizadas simultaneamente no início de cada operação 
de coleta: uma tarrafa com malha de 5,0 cm (distância entre os nós opostos), diâmetro de $15 \mathrm{~m}$ e $5 \mathrm{~kg}$ de massa foi usada nos pontos II e III e duas tarrafas pequenas de malha 1,0 e 1,5 cm (entre nós opostos), diâmetro de $8,0 \mathrm{~m}$ e $2 \mathrm{~kg}$ de massa, foram usadas nos três pontos de amostragem. A tarrafa maior foi ocasionalmente, utilizada para arrastos no leito do rio no ponto III, de modo a realizar a coleta abrangendo toda a largura do rio. Em geral, as coletas foram diurnas e duraram entre 4 e 5,5 horas. Os espécimes obtidos foram fixados em formol $10 \%$, e posteriormente transferidos para álcool a $70 \%$.

A similaridade na composição de espécies entre as assembléias de peixes dos diferentes locais de coleta e suas diferenças sazonais foi avaliada utilizando-se o coeficiente de Jaccard (MAGURRAN, 1991), Q=C/(A+BC) $\mathrm{x} 100$, onde $\mathrm{Q}=$ índice de similaridade entre os locais (ou estações sazonais) A e B; $\mathrm{A}=$ número de espécies no local ou estação sazonal A; $\mathrm{B}=$ número de espécies no local ou estação sazonal $\mathrm{B}$ e $\mathrm{C}=$ número de espécies comuns entre os locais e estações sazonais Ae B. Valores próximos de zero indicam que os locais ou estações sazonais apresentam menor similaridade e valores próximos a um significam que os locais ou estações apresentam maior similaridade na composição de espécies. Para a elaboração do dendrograma de similaridade foi utilizado o software NTSYS-PC versão 2.0 usando o método de ligação simples para o agrupamento. O coeficiente de correlação cofenético (r) foi calculado para avaliar a distorção do dendrograma em relação à matriz de similaridade obtida.

Para determinação das espécies residentes e espécies migrantes foi utilizada a constância de ocorrência (DAJOz, 1973), C = p/Px 100, onde C $=$ valor de constância da espécie, $\mathrm{p}=$ número de coletas contendo a espécie estudada e $\mathrm{P}=$ número total de coletas efetuadas. Uma espécie é considerada constante quando apresenta C $>50 \%$, acessória, quando $25 \% \leqslant \mathrm{C} \leqslant 50 \%$ e acidental, quando $\mathrm{C}<25 \%$.

A lista de espécies apresentada segue a classificação proposta por LAUDER \& LIEM (1983), com alterações propostas por BUCKUP (1998), DE PINNA (1998) e REIS et al. (2003).

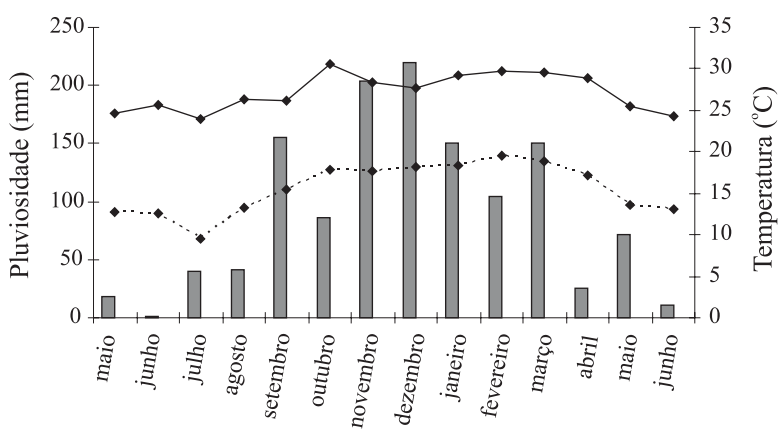

Fig. 2. Valores mensais de pluviosidade e temperaturas do ar no período entre abril de 2000 e junho de 2001 em São Carlos, São Paulo, Brasil (barras, pluviosidade; linha cheia, temperatura máxima; linha tracejada, temperatura mínima).

\section{RESULTADOS}

Foram coletados no ribeirão do Pântano 4.694 indivíduos, distribuídos em 18 famílias e 63 espécies (Tab. I). Os totais de espécies registrados para cada ponto foram: 13 no ponto I, 41 no ponto II e 49 no ponto III (Tab. I).

Das 63 espécies amostradas, apenas 6 ocorreram nos três locais de amostragem. São elas: Corydoras aeneus (Gill, 1858), Geophagus brasiliensis (Quoy \& Gaimard, 1824), Gymnotus carapo Linnaeus, 1758, Hypostomus ancistroides (Ihering, 1911), Megalechis personata (Ranzani, 1841) e Rhamdia quelen (Quoy \& Gaimard, 1824). Foram encontrados indivíduos jovens (entre 6 e $10 \mathrm{~cm}$ de comprimento padrão) das espécies Leporinus cf. friderici (Valenciennes, 1794) (canal junto ao ponto III), Prochilodus lineatus (Valenciennes, 1847) e Pimelodus maculatus Lacépède, 1803 (Ponto II).

As espécies estão distribuídas nas ordens Characiformes (7 famílias, 20 gêneros e 30 espécies), Siluriformes (5 famílias, 15 gêneros e 22 espécies), Gymnotiformes (3 famílias, 3 gêneros e 3 espécies), Perciformes (1 família, 5 gêneros e 5 espécies), Cyprinodontiformes (1 família, 2 gêneros e 2 espécies) e Synbranchiformes (1 espécie). A ordem Characiformes contribuiu com $47,62 \%$ das espécies capturadas e Siluriformes, com $34,92 \%$ do total sendo, estas as ordens que apresentaram o maior número de exemplares por família (Fig. 3).

A família Characidae, com 2.541 exemplares foi a melhor representada neste estudo (Fig. 3) e as espécies que mais contribuíram para este resultado foram Hyphessobrycon eques (Steindachner, 1882) (549 indivíduos), Cheirodon stenodon Eigenmann, 1915 (534) e Serrapinnus notomelas (Eigenmann, 1915) (358), compreendendo aproximadamente $57 \%$ do total de capturas nesta família. A familia Characidae esteve representada em sua maioria por peixes de até $10 \mathrm{~cm}$ de comprimento padrão (exceto Salmininae), presentes nos três pontos amostrados.

A segunda família melhor representada foi Loricariidae, com 596 exemplares (Fig. 3), e representada em $80 \%$ das coletas através da espécie $H$. ancistroides (481 indivíduos), presente nos três pontos e ocupando os diversos microhabitats amostrados.

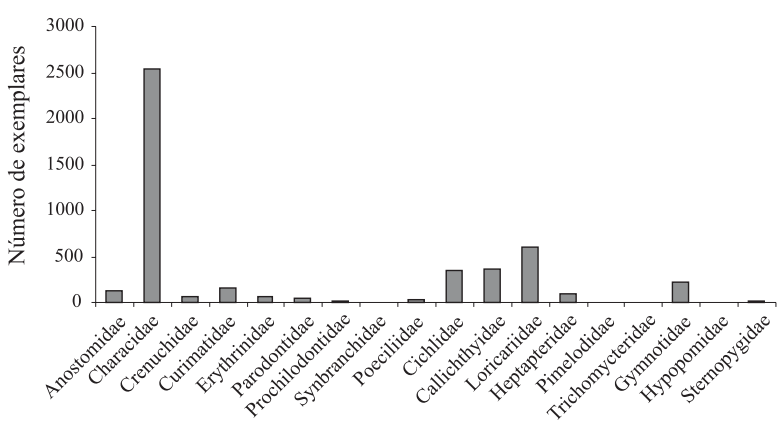

Fig. 3. Contribuição em número de indivíduos das famílias de peixes coletadas nos três pontos amostrados do ribeirão do Pântano, São Paulo, Brasil entre os meses de maio de 2000 e junho de 2001 . 
Tabela I. Lista de espécies de peixes registradas, constância e ocorrência nos pontos de amostragem no período entre maio de 2000 e junho de $2001 \mathrm{em}$ três pontos do ribeirão do Pântano, São Paulo, Brasil (PI-PII, pontos I a III).

\begin{tabular}{llll}
\hline NOME & P I & P II & P III \\
\hline
\end{tabular}

\section{CHARACIFORMES}

Characidae

Astyanax altiparanae Garutti \& Britski, 2000

Astyanax fasciatus (Cuvier, 1819)

Astyanax paranae Eigenmann, 1914

Bryconamericus stramineus Eigenmann, 1908

Gymnocorymbus ternetzi (Boulenger, 1895)

Hemigrammus marginatus Ellis, 1911

Hyphessobrycon anisitsi (Eigenmann, 1907)

Hyphessobrycon bifasciatus Ellis, 1911

Hyphessobrycon eques (Steindachner, 1882)

Moenkhausia sanctaefilomenae (Steindachner, 1907)

Oligosarcus pintoi Campos, 1945

Piabina argentea Reinhardt, 1867

Salmininae

Salminus hilarii Valenciennes, 1850

Cheirodontinae

Cheirodon stenodon Eigenmann, 1915

Serrapinnus heterodon (Eigenmann, 1915)

Serrapinnus notomelas (Eigenmann, 1915)

Crenuchidae

Characidium gomesi Eigenmann, 1909

Characidium zebra Travassos, 1956

Parodontidae

Parodon nasus Kner, 1859

Curimatidae

Cyphocharax modestus (Fernández-Yépez, 1948)

Steindachnerina insculpta (Fernández-Yépez, 1948)

Anostomidae

Leporellus vittatus (Valenciennes, 1849)

Leporinus cf. friderici (Valenciennes, 1794)

Leporinus obtusidens (Valenciennes, 1847)

Leporinus octofasciatus Steindachner, 1917

Leporinus paranensis Garavello \& Britski, 1987

Leporinus striatus Kner, 1859

Erytrhinidae

Hoplerythrinus unitaeniatus (Spix \& Agassiz, 1829)

Hoplias malabaricus (Bloch, 1794)

Prochilodontidae

Prochilodus lineatus (Valenciennes, 1847)

GYMNOTIFORMES

Hypopomidae

Brachyhypopomus sp.

Sternopygidae

Eigenmannia virescens (Valenciennes, 1842)

Gymnotidae

Gymnotus carapo Linnaeus, 1758

PERCIFORMES

Cichlidae

Laetacara sp.

Cichlasoma facetum (Jenyns, 1842)

Crenicichla cf. jaguarensis Haseman, 1911

Geophagus brasiliensis (Quoy \& Gaimard, 1824)

Tilapia rendalli (Boulenger, 1897)

SILURIFORMES

Callichthyidae

Callichthys callichthys (Linnaeus, 1758)

Corydoras cf. aeneus (Gill, 1858)

Corydoras cf. garbei Ihering, 1911

Hoplosternum littorale (Hancock, 1828)

Megalechis personata (Ranzani, 1841)

Loricariidae

Loricaria lentiginosa (Isbrücker, 1979)

Rineloricaria latirostris (Boulenger, 1900)

Hypostomus ancistroides (Ihering, 1911)

Hypostomus cf. fluviatilis (Ihering, 1964)

Hypostomus cf. paulinus (Regan, 1908)

Hypostomus regani (Ihering, 1905)

Hypostomus sp.

Hypostomus strigaticeps (Regan, 1908)

Constante

Constante

Constante

Acidental

Acessória

Constante

Constante

Constante

Constante

Acessória

Constante

Acidental

Constante

Constante

Acessória

Constante

Acessória

Constante

Constante

Acidental

Acidental

Acessória

Acidental

Acessória

Constante

Acidental

Constante

Acessória

Constante

Acessória

Constante

Acessória

Constante

Acidental

Constante

Acessória

Acidental

Constante

Acessória

Constante

Constante

Acessória

Acessória

Constante

Acessória

Constante

Constante

Constante

Acidental

Constante

Acidental

Constante

Constante

Acidental

Acessória

Constante

Constante

Acidental

Constante

Acessória

Constante

Acessória

Acessória
Acessória

Acidental

Constante

Acessória

Constante

Constante

Acessória

Acessória

Acessória

Acidental

Acidental Acidental

Hisonotus depressicauda (Miranda-Ribeiro, 1918)

Hisonotus insperatus Britski \& Garavello, 2003 


\begin{tabular}{|c|c|c|c|}
\hline Tabela I (cont.) & & & \\
\hline NOME & P I & P II & P III \\
\hline Trichomycteridae & & & \\
\hline Parastegophilus paulensis (Miranda-Ribeiro, 1946) & & & Acidental \\
\hline $\begin{array}{l}\text { Paravandellia oxyptera Miranda-Ribeiro, } 1912 \\
\text { Heptapteridae }\end{array}$ & & Acidental & \\
\hline Imparfinis schubarti (Gomes, 1956) & & Acidental & Acidental \\
\hline Phenacorhamdia tenebrosa (Schubart, 1964) & & Acidental & \\
\hline Pimelodella gracilis (Valenciennes, 1835) & & & Acidental \\
\hline $\begin{array}{l}\text { Rhamdia quelen (Quoy \& Gaimard, 1824) } \\
\text { Pimelodidae }\end{array}$ & Constante & Acidental & Acidental \\
\hline Pimelodus maculatus Lacépède, 1803 & & Acidental & Acidental \\
\hline $\begin{array}{l}\text { CYPRINODONTIFORMES } \\
\text { Poeciliidae }\end{array}$ & & & \\
\hline Phalloceros caudimaculatus (Hensel, 1868) & Constante & & \\
\hline Poecilia reticulata Peters, 1859 & Acessória & & \\
\hline $\begin{array}{l}\text { SYNBRANCHIFORMES } \\
\text { Synbranchidae }\end{array}$ & & & \\
\hline Synbranchus marmoratus (Bloch, 1795) & & Acessória & Acidental \\
\hline $\mathrm{n}^{\circ}$ de espécies & 13 & 41 & 49 \\
\hline total de espécies constantes & 11 & 18 & 17 \\
\hline total de espécies acessórias & 2 & 11 & 14 \\
\hline total de espécies acidentais & 0 & 12 & 18 \\
\hline
\end{tabular}

A terceira família foi Callichthyidae com 368 exemplares (Fig. 3), onde a espécie M. personata (183 indivíduos) ocorreu em maior número, enquanto Callicthys, Corydoras e Hoplosternum sempre ocorreram em menor número de indivíduos.

Cichlidae foi a quarta família, representada por 351 indivíduos coletados (Fig. 3). De suas espécies, $G$. brasiliensis representou $80,3 \%$ do total, e foi encontrada em todos os pontos de coleta contra $19,7 \%$ das demais.

A família Heptapteridae foi representada por 96 exemplares, sendo Rhamdia cf. quelen a espécie mais coletada (86 exemplares). Pimelodidae contribuiu apenas com 4 exemplares de Pimelodus maculatus.

Gymnotidae apresentou 216 exemplares. As famílias cujas espécies ocorreram em baixo número de exemplares foram: Hypopomidae (1), Trichomycteridae (2), Synbranchidae (5), Prochilodontidae (13), Sternopygidae (21), Poeciliidae (38), Parodontidae (40) e Erythrinidae (60) (Fig. 3). Dentre estas famílias, Erythrinidae e Trichomycteridae apresentaram duas espécies cada, enquanto as demais famílias estiveram representadas por apenas uma espécie.

No ponto I, ocorreram 6 espécies exclusivas: Astyanax paranae Eingenmann, 1914, Characidium gomesi Eigenmann, 1909, Phalloceros caudimaculatus (Hensel, 1868), Hyphessobrycon anisitsi (Eigenmann, 1907), Poecilia reticulata Peters, 1859 e Tilapia rendalli (Boulenger, 1897). O ponto I apresentou maior porcentagem de espécies constantes, enquanto os pontos II e III demonstraram valores percentuais mais baixos e semelhantes entre si como pode ser visto na Fig. 4. No ponto II, a maioria das espécies consideradas na categoria constante é de pequeno porte (até $15 \mathrm{~cm})$. As exceções foram Hoplias malabaricus (Bloch, 1794), Geophagus brasiliensis (Quoy \& Gaimard, 1824), Gymnotus carapo Linnaeus, 1758 e Crenicichla cf. jaguarensis Haseman, 1911 que apresentam porte maior.

O ponto II também apresentou 6 espécies exclusivas: Hemigrammus marginatus Ellis, 1911, Leporinus obtusidens (Valenciennes, 1847), L. paranensis Garavello \& Britski, 1987, Oligosarcus pintoi Campos, 1945, Phenacorhamdia tenebrosa (Schubart, 1964), Paravandellia oxyptera Miranda-Ribeiro, 1912 e C. cf. jaguarensis.
No ponto III foram encontradas 16 espécies exclusivas: Hyphessobrycon bifasciatus Ellis, 1911, Bryconamericus stramineus Eigenmann, 1908, Salminus hilarii Valenciennes, 1850, Leporinus octofasciatus Steindachner, 1917, Cyphocharax modestus (FernándezYépez, 1948), Callichthys callichthys (Linnaeus, 1758), Hisonotus insperatus Britski \& Garavello, 2003, Hypostomus cf. fluviatilis (Ihering, 1964), H. cf. paulinus (Regan, 1908), H. regani (Ihering, 1905), H. strigaticeps (Regan, 1908), Loricaria lentiginosa (Isbrücker, 1979), Parastegophylus paulensis (Miranda-Ribeiro, 1946), Pimelodella gracilis (Valenciennes, 1835), Brachyhypopomus sp. e Laetacara sp.

Algumas espécies como Megalechis personata e $G$. brasiliensis mantiveram-se constantes nos três pontos. Hypostomus ancistroides também foi constante nos pontos I e III, porém houve dificuldade na identificação de exemplares juvenis, fato esse que não permitiu a sua determinação como constante no ponto II, tendo sido classificada como acessória. Nos pontos II e III, Hyphessobrycon eques, Serrapinnus notomelas e Cheirodon stenodon foram constantes.

No canal junto ao Ponto III foram coletados exemplares juvenis das espécies Leporinus friderici, Prochilodus lineatus e Pimelodus maculatus que ainda foram encontrados no ponto II. Neste ultimo ponto a presença de juvenis dessas espécies sempre ocorreu em menor frequiência que $P$. maculatus $\mathrm{e}$. lineatus que sempre foram espécies mais freqüentes neste ponto de coletas.

A figura 4 apresenta os valores obtidos com a análise da constância das espécies nos três pontos investigados no ribeirão do Pântano. Pelo gráfico de barras desta figura pode-se observar que o ponto I reuniu o maior número de espécies constantes e o menor número de espécies acessórias deste estudo. Neste ponto não foram observadas espécies acidentais. Nos demais pontos o número de espécies constantes e acessórias foi equivalente, enquanto nos demais pontos de coleta o número de espécies acidentais ficou entre $30 \mathrm{e} 40 \%$.

Com a aplicação do índice de similaridade de Jaccard se obteve um dendrograma (Fig. 5). O coeficiente de correlação cofenético apresentou valor satisfatório $(\mathrm{r}=$ 0.979), o que indica uma distorção mínima da matriz de 


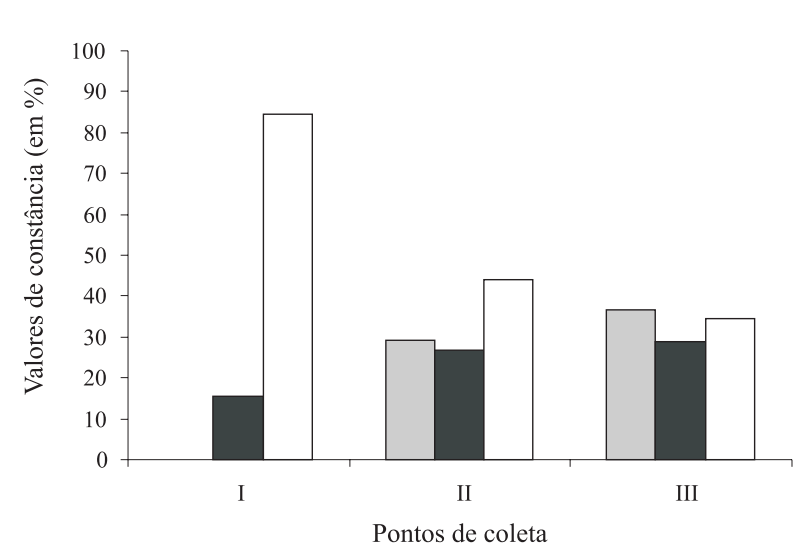

Fig. 4. Valores de constância das espécies nos três pontos de coleta no ribeirão do Pântano, São Paulo, Brasil entre os meses de maio de 2000 e junho de 2001. Espécies constantes (barras brancas), espécies acessórias (barras negras) e espécies acidentais (barras cinza).

similaridade. Com base no dendrograma de similaridade, pode-se observar que o ponto de coleta situado a montante do salto do Pântano apresentou baixa similaridade, quando comparado aos dois pontos situados a jusante desse salto. As estações chuvosa e seca apresentaram similaridade elevada nos pontos II e III.

\section{DISCUSSÃO}

BRITSKI (1972) estima que cerca de 90 a $95 \%$ das espécies de peixes que ocorrem nos ambientes de água doce do Estado de São Paulo pertencem a superordem Ostariophysi. Os resultados encontrados neste estudo indicam que esta superordem representa $87,3 \%$ do total de 63 espécies capturadas, portanto muito próximo das estimativas apresentadas por aquele autor.

Para fins comparativos e balizamento deste estudo, os dados apresentados por CASTRO \& CASATTI (1997) para um afluente do rio Pardo, incluem 19 espécies pertencentes a 15 gêneros, distribuídas em 9 famílias e em quatro ordens, num universo estimado de cerca de 100 espécies reconhecidas para o rio Pardo. Por outro lado, este estudo no ribeirão do Pântano registrou 63 espécies, o que talvez corresponda, quando considerada a representatividade específica, a aproximadamente $62 \%$ da ictiofauna atual da bacia do rio Pardo.

CASTRO (1999) indica que aproximadamente $85 \%$ da composição da ictiofauna de riachos brasileiros é normalmente formada pelas ordens Characiformes e Siluriformes, o que foi corroborado por este estudo no ribeirão do Pântano. Outros autores que trabalharam na bacia do Alto Paraná encontraram valores entre 80 e $89 \%$ para essas ordens, (Gomes \& Azevedo, 1960 no rio Camanducaia; GARUtTI, 1988 no córrego Barra Funda; Pavanelli \& Caramaschi, 1997 nos ribeirões São Pedro e Caracu; CAstro \& CASATti, 1997 em afluente do rio Pardo e BENNEMANn et al., 2000, no rio Tibagi). Entretanto, UiEDA (1984) encontrou apenas $76,4 \%$ da ictiofauna composta por Characiformes e Siluriformes no ribeirão Tabajara; SABINO \& CASTRO (1990) reportam 66,6\% destas ordens em riacho da Mata Atlântica, enquanto CASATTI \& CASTRO (1998) relatam que, da composição total da ictiofauna de

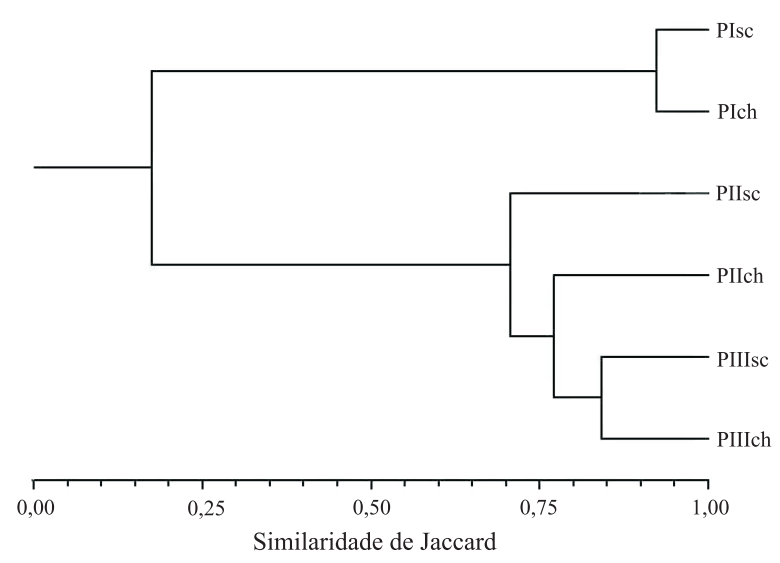

Fig. 5. Dendrograma de similaridade de espécies entre os pontos amostrados nas estações seca e chuvosa no ribeirão do Pântano, São Paulo, Brasil entre os meses de maio de 2000 e junho de 2001. (ch, estação chuvosa; PI, PII, PIII, pontos I a III; sc, estação seca).

um trecho em corredeiras do rio São Francisco, 95,2\% é composto por peixes das ordens Characiformes e Siluriformes.

O cálculo da constância tem sido utilizado por diversos autores (UIEDA, 1984; GARUTTI, 1988; SABINO \& Castro, 1990 e Galleti Jr. et al., 1990) para exibir a participação das espécies nas amostragens e caracterizar as assembléias de peixes nos locais amostrados. GARUTTI (1988) justifica que as alterações no número de indivíduos das assembléias geralmente estão relacionadas a variações sazonais, que por sua vez estariam associadas aos seguintes fatores: (a) físico-químicos do ambiente; (b) movimentação de cardumes ou indivíduos e (c) período de atividade de cada espécie. Aquele autor ainda constata que o número de espécies se eleva na razão direta do incremento do volume de água quando se vai da nascente em direção à foz.

$\mathrm{O}$ fato dos maiores índices de riqueza em espécies terem sido verificados nos pontos II e III pode estar associado a preservação da vegetação ripária e ao maior volume de água disponível nessas áreas. Assim sendo, haveria uma maior disponibilidade de locais para refúgio da ictiofauna residente, notadamente para aquelas espécies de menor porte, seguidas por espécies acessórias ou acidentais, que normalmente ocupam as lagoas temporárias e margens alagadas do ribeirão do Pântano no período úmido regional. O ponto I situado a montante do salto do Pântano revelou riqueza inferior aos outros pontos, talvez em razão desse salto se constituir em uma barreira que pode ter produzido o isolamento dessas duas seções do rio do Pântano (e impedido a migração da ictiofauna para montante da drenagem).

Paravandellia oxyptera e Parastegophilus paulensis que, de acordo com BRITSKI (1972) são as únicas espécies parasitas de peixes conhecidas que ocorrem no Estado de São Paulo, foram registradas nos pontos II e III, respectivamente. Paravandellia oxyptera, como relata MiRANDA-RIBEIRo (1954), foi encontrada presa ao corpo de exemplares de Prochilodus lineatus. Parastegophilus paulensis, por outro lado, ataca exemplares de Salminus maxillosus e Brycon sp. (IHERING, 1930).

Tanto a espécie G. brasiliensis, que esteve presente 
no ponto I em áreas com acúmulo de sedimentos e detritos, quanto Prochilodus lineatus, que são espécies reconhecidamente detritívoras-invertívoras (HAHN \& CunHA, 2005), podem ter se beneficiado da oferta deste recurso continuamente disponível no ponto II, onde a baixa velocidade da água permite o depósito de sedimentos. No ponto III, onde os bancos de sedimentos são escassos e a correnteza é rápida, $P$. lineatus foi capturado em trânsito entre o ponto II e o rio Mogi-Guaçu. No ponto II, em águas mais calmas foram ainda registradas espécies piscívoras como Hoplias malabaricus e Oligosarcus pintoi (LoureIro \& HaHN, 1996). Essas assertivas coincidem com as discussões de UIEDA (1984), que encontrou estas espécies nos trechos de remanso e entre a vegetação ribeirinha do ribeirão Tabajara. As espécies de Hypostomus foram mais bem representadas em ambientes com blocos de rochas no substrato e em ambiente torrentoso, ao invés de áreas de remanso em fundo arenoso. As informações aqui apresentadas corroboram as observações sobre Hypostomus ancistroides feitas por GoMES \& AZEVEDo (1960) e UIEDA (1984), que encontraram esta espécie (inclusive exemplares jovens) habitando águas correntes e de fundo pedregoso. Todos os exemplares de $H$. ancistroides presentes no ponto III foram coletados no canal do ribeirão, onde a velocidade da água é normalmente baixa. No ponto II, nas regiões de fundo arenoso foram encontrados loricariídeos de pequeno porte, sempre ocupando a vegetação. Characidium gomesi ocorreu apenas no ponto I, distribuída sobre o substrato rochoso e em áreas de baixa profundidade. A captura desses exemplares se deu com o uso das tarrafas de malha pequena e apenas os indivíduos maiores foram capturados. O resultado foi semelhante no ponto III para Characidium zebra. Por outro lado, os exemplares de porte reduzido desta espécie foram capturados com o uso de peneira de malha fina, tanto na vegetação como no canal do ponto III. No ponto II, apenas três indivíduos de $C$. zebra foram encontrados. GOMES \& AzEvEDo (1960) assinalam a ocorrência de $C$. fasciatum entre as rochas do fundo e $C$. gomesi apenas nas áreas de maior altitude.

Durante o período úmido foram encontrados exemplares juvenis (entre 6 e $10 \mathrm{~cm}$ de comprimento padrão) das espécies Leporinus friderici, Prochilodus lineatus e Pimelodus maculatus tanto no canal junto ao ponto III como no ponto II, onde $P$. maculatus e $P$. lineatus sempre foram mais freqüentes. Estas áreas provavelmente ofereçam abrigo aos exemplares juvenis dessas espécies e àquelas outras da ordem Characiformes.

GALETTI JR et al. (1990) encontraram formas juvenis de algumas das espécies coletadas no presente estudo na lagoa do Diogo e do Infernão, ambas situadas na Estação Ecológica do Jataí, dentro da bacia do rio MogiGuaçu. Partindo da premissa que os juvenis das espécies de Characiformes supracitadas passam estágios de seu desenvolvimento em lagoas marginais desse sistema hidrográfico, a presença destes juvenis nos ribeirões tributários da bacia do rio Mogi-Guaçu sugere que estes estejam utilizando estes ambientes como abrigo. Assim sendo, estes ribeirões estariam secundariamente integrados ao sistema utilizado pela ictiofauna para a desova.
Agradecimentos. Agradecemos aos colegas do Laboratório de Ictiologia Sistemática do DEBE-UFSCar Alexandre K. de Oliveira e José L. Birindelli pelo auxílio nas atividades de coleta e de laboratório. Aos Prof. Dr. Orlando M. Filho e ao auxiliar técnico Luis H. da Silva do Laboratório de Citogenética do Departamento de Genética e Evolução pelo auxílio no trabalho de campo. Aos Drs. Luis C. Bertollo, Pedro M. Galetti Jr. e Manoel M. Dias pela leitura e críticas ao manuscrito. À Comissão de Aperfeiçoamento de Pessoal de Ensino Superior (CAPES) pela bolsa de mestrado concedida ao primeiro autor. Ao Conselho Nacional de Desenvolvimento Científico e Tecnológico (CNPq) pela bolsa de pesquisa concedida ao segundo autor.

\section{REFERÊNCIAS BIBLIOGRÁFICAS}

Bennemann, S. T.; Shibatta, O. A. \& Garavello, J. C. 2000 Peixes do rio Tibagi, uma abordagem ecológica. Londrina, UEL Editora. 62p.

Böhlke, J. E.; Weitzmann, S. H. \& Menezes, N. A. 1978. Estado atual da sistemática dos peixes de água-doce da América do Sul. Acta Amazônica 8(4):657-677.

Britski, H. A. 1972. Peixes de água doce do Estado de São Paulo - Sistemática. In: Comissão interestadual da bacia ParanáUruguay. Poluição e Piscicultura, notas sobre ictiologia, poluição e piscicultura. São Paulo, FSPUSP e Instituto de Pesca. p.79-108.

Buckup, P. A. 1998. Relationships of the Characidiinae and phylogeny of characiforms fishes (Teleostei, Ostariophysi). In: Malabarba, L. R.; Reis, R. E.; Vari, R.; Lucena, Z. M. \& Lucena, C. A. S. Phylogeny and classification of neotropical fishes. Porto Alegre, EDIPUCRS. p.123-144.

Casatti, L. \& CAStro, R. M. C. 1998. A fish community of the São Francisco River headwater riffles, southeastern Brazil Ichthyological Exploration of Freshwaters 9(3):229-242.

Casatti, L; Langeani, F. \& Castro, R. M. C. 2001. Peixes de riacho do Parque Estadual Morro do Diabo, bacia do Alto Rio Paraná, SP. Biota Neotropica 1(1-2):1-15.

CAstro, R. M. C. 1999. Evolução da ictiofauna de riachos sulamericanos: padrões gerais e possíveis processos causais. In: Caramaschi, E. P.; Mazzoni, R. \& Peres-Neto, P. R. eds. Série Oecologia Brasiliensis, Ecologia de peixes de riachos. Rio de Janeiro, PPGE-UFRJ. p.139-155.

Castro, R. M. C. \& Casatti, L. 1997. The fish fauna from a small forest stream of the upper Paraná river basin, southeastern Brazil. Ichthyological Exploration of Freshwaters 7(4):337-352

DAJOZ, R. 1973. Ecologia Geral. São Paulo, EDUSP. 474p.

DE PINnA, M. C. C. 1998. Phylogenetic relationships of neotropical Siluriformes: Historical overview and synthesis of hypotheses. In: Malabarba, L. R.; Reis, R. E.; Vari, R.; Lucena, Z. M. \& Lucena, C. A. S. Phylogeny and classification of neotropical fishes. Porto Alegre, EDIPUCRS. p. 279-330.

Esteves, K. E. \& Aranha, J. M. R. 1999. Ecologia trófica de peixes de riachos. In: Carasmaschi, E. P.; Mazzoni, R. \& PeresNeto P. R. eds. Série Oecologia Brasiliensis: Ecologia de peixes de riachos. Rio de Janeiro, PPGE-UFRJ. p.157-182.

Esteves, K. E. \& Galetti JR, P. M. 1995. Food partitioning among some characids of a small brazilian floodplain lake from the Paraná River Basin. Environmental Biology of Fishes 42:375-389

Galetti JR, P. M.; Esteves, K. E.; Lima, N. N. W.; Mestriner, C. A.; Cavallini, M. M.; Cesar, A. C. G. \& Miyazawa, C.S. 1990 Aspectos comparativos da ictiofauna de duas lagoas marginais do rio Mogi-Guaçu (Alto Paraná - Estação Ecológica do Jataí, SP). Acta Limnologica Brasiliensia 3:865-885.

GarutTi, V. 1988. Distribuição longitudinal da ictiofauna em um córrego da região noroeste do estado de São Paulo, bacia do rio Paraná. Revista Brasileira de Biologia 48(4):747-759.

Godoy, M. P. 1954. Locais de desova de peixes num trecho do rio Mogi Guaçu, estado de São Paulo, Brasil. Revista Brasileira de Biologia 14(4):375-396.

GoDOY, M. P. 1962. Marcação, migração e transplantação de peixes marcados na bacia do rio Paraná superior. Arquivos do Museu Nacional Rio de Janeiro 52:105-113.

Gomes, A. L. \& Azevedo, P. 1960. Os peixes de Monte Alegre do 
Sul, Estado de São Paulo. Papéis Avulsos de Zoologia 14:133-151.

Hahn, N. S. \& CunHa, F. 2005. Feeding and trophic ecomorphology of Satanoperca pappaterra (Pisces, Cichlidae) in the Manso Reservoir, Mato Grosso State, Brazil. Brazilian Archives of Biology and Technology 48(6):1007-1012.

IHERING, R. 1929. Da vida dos peixes. Ensaios e scenas de pescaria. São Paulo, Melhoramentos. 150p.

IHERING, R. 1930. Notas ecológicas referentes a peixes d'água doce do Estado de S. Paulo e descripção de 4 espécies novas. Archivos do Instituto Biológico 3:93-104.

Lauder, G. V. \& Liem, K. F. 1983. The evolution and interrelationships of the actinopterygian fishes. Bulletin Museum of Comparative Zoology 150(3):95-197.

Loureiro, V. E. \& HaHn, N. S. 1996. Dieta e atividade alimentar da traíra, Hoplias malabaricus (Bloch, 1794) (Osteichthyes, Erythrinidae), nos primeiros anos de formação do reservatório de Segredo, PR. Acta Limnológica Brasiliensia 8:195-205.

Lowe-McConnell, R. H. 1999. Estudos ecológicos em comunidades de peixes tropicais. São Paulo, EDUSP. 536p.

Magurran, A. E. 1991. Ecological diversity and its measurement. New York, Chapmann \& Hall. 179p.

Meschiatti, A. J. 1995. Alimentação da comunidade de peixes de uma lagoa marginal do rio Mogi Guaçu, SP. Acta Limnológica Brasiliensia 7:115-137.

Miranda-Ribeiro, P. M. 1954. Catálogo dos peixes do Museu Nacional - I - Pygidiidae Eigenmann \& Eigenmann, 1888. Publicações Avulsas do Museu Nacional 15:1-17.

Nomura, H. \& Müeller, I. M. DE M. 1980. Biologia do cascudo, Plecostomus hermanni, Ihering, 1905 do rio Mogi-Guaçu,
São Paulo (Osteichthyes, Loricariidae). Revista Brasileira de Biologia 40(4):267-275.

Nomura, H.; Pozzi, R. \& Manreza, F. A. 1972. Caracteres merísticos e dados biológicos sobre o mandi-amarelo, Pimelodus clarias (Bloch, 1782), do Rio Mogi-Guaçu (Pisces, Pimelodidae) Revista Brasileira de Biologia 32(1):1-14.

Pavanelli, C. S. \& Caramaschi, E. P. 1997. Composition of the ichthyofauna of two small tributaries of the Paraná river, Porto Rico, Paraná State, Brazil. Ichthyological Exploration of Freshwaters 8(1):23-31.

Reis, R. E.; Kullander, S. O. \& Ferraris, C. J. 2003. Check list of the Freshwater fishes of South and Central America. Porto Alegre, EDIPUCRS. $729 \mathrm{p}$.

Sabino, J. \& CASTRo, R. M. C. 1990. Alimentação, período de atividade e distribuição espacial dos peixes de um riacho da floresta Atlântica (Sudeste do Brasil). Revista Brasileira de Biologia 50(1):23-36

Schubart, O. 1943. A pesca na Cachoeira de Emas do rio MogiGuaçu durante a piracema de 1942-1943. Boletim Indústria Animal 6(4): 93-116.

Schubart, O. 1962. Lista dos peixes da bacia do rio Mogi-Guaçu. Atas Sociedade Biológica Rio de Janeiro 6(3):26-32.

Schubart, O. 1964a. Sobre algumas Loricariidae da Bacia do rio Mogi-Guaçu. Boletim Museu Nacional, Nova Série, Zoologia (251):1-19.

Schubart, O. 1964b. Duas novas espécies de peixe da família Pimelodidae do Rio Mogi-Guaçu (Pisces, Nematognathi). Boletim Museu Nacional, Nova Série, Zoologia (244):1-22.

UiedA, V. S. 1984. Ocorrência e distribuição dos peixes em um riacho de água doce. Revista Brasileira de Biologia 44(2):203-213.

Recebido em junho de 2005. Aceito em março de 2007. ISSN 0073-4721

Artigo disponível em: www.scielo.br/isz 